\title{
Cultura popular e educação, uma experiência de visitação ao Museu Casa do Pontal
}

DOI: https://doi.org/10.22409/pragmatizes.v11i20.45577

\section{Lia Calabre ${ }^{1}$ \\ Rosely Coutinho ${ }^{2}$}

Resumo: A cultura atua como um componente ativo e aliado ao processo de ensino aprendizagem, o que justifica a formação do indivíduo crítico e participativo de uma sociedade. Muito além de gerar condições para a apropriação de conhecimentos em sala de aula, a educação precisa fazer o alinhamento para o debate em torno da atuação do aprendiz em novas experiências culturais. $O$ Museu Casa do Pontal, classificado como um museu de arte popular é um lugar de educação e cultura que colabora positivamente com o processo construtivo dos estudantes. O presente artigo busca contribuir com as reflexões sobre a relação cultura e educação, com a apresentação das experiências de vivências extramuros, especificamente concretizadas a partir da visitação por turmas do ensino fundamental I, de escolas regulares da rede pública do município do Rio de Janeiro ao referido museu. $O$ artigo faz uma rápida abordagem sobre a educação não formal, mostra o espaço do museu, reflete sobre a educação museal com o apoio da arte educação e procede a descrição das situações nas quais os alunos interagem, trocam e experimentam momentos de aprendizagem, prazer e deleite.

Palavras-chave: Cultura popular; educação; Museu Casa do Pontal; educação museal.

\section{Cultura y educación popular, una experiencia de visita al Museo Casa do Pontal}

Resumen: La cultura actúa como un componente activo aliado al proceso de enseñanza-aprendizaje, lo que justifica la formación del individuo crítico y participativo en la sociedade. Mucho más que generar condiciones para la apropriación del conocimiento en el aula, la educación necessita alinearse con el debate en torno al desempeño de la participacion del alumno en nuevas experiencias culturales. El museo Casa do Pontal, classificado como museo de arte popular, es un lugar de educación y cultura que colabora positivamente con el proceso de aprendizaje de los estudiantes. Este artículo busca contribuir a las reflexiones sobre la relación entre cultura y educación, a partir de la presentación de experiências extramuros. La investigación se realizo a partir de la visita al Museo de grupos de escuelas públicas de la cuidad de Río de Janeiro. El artículo analisa brevemente la educación no formal, muestra el espacio del museo, reflexiona sobre la educación museística com el

\footnotetext{
${ }^{1}$ Lia Calabre. Doutora em História (UFF), Professora do PPG Memória e Acervos da FCRB e do PPG Cultura e Territorialidades - UFF, Brasil.E-mail: liacalabre@gmail.com.br - https://orcid.org/00000002-7586-7210

${ }^{2}$ Rosely Gonçalves Coutinho. Mestra em Memória e Acervos (FCRB), Professora regente do Ensino Fundamental I - Município do Rio de Janeiro, Brasil E-mail:liucoutinho@yahoo.com.br
} 
apoyo de la educación artística y describe las situaciones en las que los etudiantes interactúan, intercambian y experimentam momentos de aprendizaje y placer.

Palabras clave: Cultura popular; educación, Museo Casa do Pontal, educación museal.

Popular culture and education, a visitation experience to the Casa do Pontal Museum

\begin{abstract}
Culture acts as an active component allied with the teaching-learning process, which justifies the formation of the critical and participative individual in society. Much more than creating conditions for classroom learning, education needs to establish the debate about learner participation in new cultural experiences. The Casa do Pontal Museum is classified as a popular art museum, being a place of education and culture that positively collaborates with the students' learning process. This article aims to contribute to the reflections on the relationship between culture and education, based on the presentation of experiences from outside the walls. The research was carried out from the visit to the Casa do Pontal Museum by elementary school groups from regular public schools in the city of Rio de Janeiro. The article briefly discusses non-formal education, shows the museum's space, reflects on museum education with the support of art education and describes the situations in which students interact, exchange and experience moments of learning, pleasure and treat.
\end{abstract}

Keywords: Popular culture; education; Casa do Pontal Museum; museal education.

\title{
Cultura popular e educação, uma experiência de visitação ao Museu Casa do
}

\section{Pontal}

O presente artigo é construído a

partir da perspectiva de que as experiências de vivências extramuros, em especial quando essas se dão no campo da cultura, têm um papel fundamental e diferenciado dentro dos tradicionais processos formais de aprendizagem.

Nessa direção, abordaremos aspectos da categoria de educação não formal, a qual possibilita que os conteúdos a serem explorados na produção de vários conhecimentos, venham ao indivíduo como uma leitura de mundo, a partir das situações que o cercam. Crítico aos métodos tradicionais de ensino o pedagogo e educador francês Célestin Freinet (1896-1966), importante referência ${ }^{3}$ no início do século $X X$, para os que lutam por uma escola democrática, aponta para a importância de modernizar os métodos escolares de ensino,

\footnotetext{
${ }^{3}$ Freinet desenvolveu uma técnica pedagógica baseada na experimentação e na documentação, almejando uma prática educacional centrada na criança, com o intuito de formar crianças ativas e dinâmicas. Sua pedagogia busca promover os direitos das crianças, dos alunos e dos professores. (FREINET, Celestin. Aprendizagem em diferentes perspectivas. 2015) Disponível em: https://educimat.cefor.ifes.edu.br/images/storie s/Publica\%C3\%A7\%C3\%B5es/Livros/Livro-1Aprendizado-em-diferentesperspectivas_2015.pdf\#page=116 Acesso em: 10 jan. 2020.
} 
buscando fazer com que as atividades educativas propostas aos estudantes sejam ligadas às situações da vida. No seu fazer pedagógico, defendia e desenvolvia uma rotina escolar pautada em aulas passeio. Nesse caso, Freinet indicava que era negativa a permanência constante do discente em ambiente fechado, ou seja, apenas em salas de aula. $\mathrm{Na}$ construção do conhecimento observava o valor da descoberta e de novas sensações. Tais contribuições motivam a reflexão de muitos dos profissionais da educação atentos aos desdobramentos possíveis de tais atividades nos processos de aprendizagem.

O sentido da educação não formal para a construção da formação integral da pessoa ganha relevância nas ações educativas quando estas são realizadas em espaços capazes de produzir relações de identidade e pertencimento.Aqui necessitamos abrir um parêntesis para explicitarmos que, especificamente nesse artigo, estamos buscando um diálogo com experiências vivenciadas com alunos da rede pública de educação do município do Rio de Janeiro, mais especificamente da zona oeste da cidade com um museu de cultura popular também localizado na mesma região: o Museu Casa do Pontal. Um pouco inspiradas por Freinet, os alunos aqui são pensados não como indivíduos isolados, mas como integrantes de uma comunidade maior, marcada por processos cotidianos que acentuam e reforçam as múltiplas e graves desigualdades presentes na sociedade brasileira.

Dentro dessa perspectiva o acesso, talvez mais que isso, a explicitação, a publicização, da riqueza, da dinâmica e da diversidade da cultura popular cumprem um importante papel na construção de uma sociedade mais democrática, mais inclusiva, mais próxima da própria realidade.

Os museus, são nossos espaços de guarda da memória social. Segundo a definição da Lei $n^{\circ} 11.904$, de 14/01/2009, que institui o Estatuto de Museus, essas são instituições que "conservam, investigam, comunicam, interpretam e expõem, para fins de preservação, estudo, pesquisa, educação, contemplação e turismo, conjuntos e coleções..." .

O movimento de comunicação e percepção da cultura popular em 
CALABRE, Lia; COUTINHO, Rosely. Cultura popular e educação, uma experiência de visitação ao Museu Casa do Pontal. PragMATIZES -

Revista Latino-Americana de Estudos em Cultura, Niterói/RJ, Ano 11, n.

20, p. 90-108, março 2021

museus, tanto pelo acervo, como pela condução da visitação que é proporcionada por alguns desses ambientes culturais, tem uma potencialidade especial de gerar processos de identidades, em especial em alguns segmentos da sociedade. Em alguns desses espaços, os acervos têm o potencial de promover trocas e diálogos, entre os visitantes, a respeito da compreensão de determinado patrimônio ou da apropriação de uma significação diversa.

\section{Educação e Museu}

O Museu Casa do Pontal como lugar de educação e cultura, segundo Angela Mascelani, atual diretora da instituição, é considerado o mais significativo museu de arte popular do Brasil (MASCELANI, 2009). Seu espaço de visitação colabora positivamente com 0 processo educativo de estudantes das redes públicas e particulares de ensino, recebendo ainda a visita de grupos provenientes de Organizações Não Governamentais (ONGs), de grupos religiosos e de turistas, além do público em geral, formado por visitantes independentes.

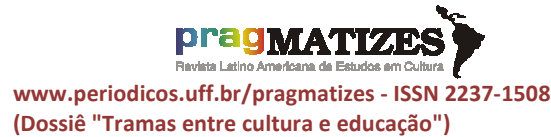

$\mathrm{O}$ acervo do referido museu foi formado em quarenta anos de pesquisa pelo designer francês Jacques Van de Beuque (1922-2000), que conheceu vários dos artistas ali presentes, durante inúmeras viagens pelo Brasil. Tal estruturação teve início na década de 1950 e, a partir de então, estendeu-se com forma de coleção. Hoje o acervo é composto por cerca de 9.000 peças, de 300 artistas, oriundos de vários estados brasileiros. Seu espaço para exposições temporárias e permanentes abriga obras que representam cenas e atividades do cotidiano sejam festivas, imaginárias e religiosas ou ainda de trabalho, de diversas partes do país.

O número de obras em exibição também reforça a compreensão de que a arte popular é feita em todo o país e não diz respeito a um único estilo de arte. Trata-se, mais propriamente, de um campo de arte, que demarca a origem social daquele indivíduo que é artista. (MASCELANI, 2014, p. 7).

Encontrada nas mais diversas regiões do país, a arte popular de acordo com Poel (2012, p. 209-211) testemunha que "a prática artística do mestre popular faz parte de seu cotidiano e tem laços essenciais com a cultura e a história de sua comunidade e sua religião". Entendendo ainda que 
"na arte do povo, o social, o econômico, o geográfico, o religioso, o estético e o funcional se complementam de modo natural e dinâmico. Na hora de criar, o artista popular, na sua condição marginal, nos surpreende pela inventividade pessoal e espontânea". (Idem)

Nesse contexto, notadamente sobre a arte que compõem o acervo do Museu Casa do Pontal, Frota discorre que:

Importa inicialmente esclarecer que os objetos aqui representados nada têm de 'rústico', 'pitoresco', 'tosco', 'primitivo' ou conceitos de atribuições similares. Estes são frutos de culturas com valores próprios, critérios de gosto e aperfeiçoamento próprios, que demonstram possuir invenção formal, mestria técnica e fruição estética [...] $\mathrm{Na}$ verdade, o que nos interessa para além de qualquer codificação é a pessoa destes artistas, pela reformulação que sem saber nos propõem, no tocante à sacralização das artes que a Renascença nos legou. São eles indivíduos cuja criatividade espelha um viver assumido, onde a imaginação reintegra e reinventa os objetos do existir, modificando-os e modificando-se. Homens e mulheres em que não há distinção entre o ser e o fazer, que não dissociam a arte da vida. (FROTA, 1976, apud POEL, 2012, p. 209).

Ainda na perspectiva de Frota (2012, p. 209) no que se refere ao acervo do Museu Casa do Pontal "o que interessa para além de qualquer codificação é a pessoa destes artistas", e como tal, Noemisa Batista dos Santos, ceramista há mais de cinquenta anos no Vale do Jequitinhonha - MG desenvolve uma técnica de maneira singular. Expõe obras específicas da grande representatividade da vida simples e do cotidiano. Utiliza barro da região e técnicas apuradas de modelagem, tratamento, secagem, que particulariza suas peças com flores, bolinhas (sucesso na percepção das crianças) e outros detalhes que transborda de poesia e delicadeza. Com a arte figurativa, dificilmente reproduz cenas que não sejam do seu mundo, do próprio universo. Recorrente nas temáticas consideradas universais, que permeiam o cotidiano de pessoas comuns, observa-se em suas peças as fases costumeiramente identificadas no desenvolvimento humano, inclusive, é comum que construa seu autorretrato nas situações do dia a dia.

As estratégias das práticas estéticas contemporâneas variam: cada artista escolhe o meio em que a obra se fará, mobilizado pelos signos que lhe pedem passagem na experiência que ele vive do meio em questão. $\mathrm{O}$ trabalho se completará com a criação de uma fórmula singular para decifrá-los, ou seja, trazê-los do invisível para o visível. (ROLNIK, 2002, p. 46). 
Dispostas num ambiente interno de $1.500 \mathrm{~m}^{2}{ }^{4}$, as obras do acervo do Museu Casa do Pontal ficavam organizadas em galerias com setores divididos em 12 temáticas, quais sejam: Profissões; Mestre Vitalino; Vida Rural; Ciclo da Vida; Brasil Festa Popular; Jogos e Diversão; Circo; Arte incomum; Arte Erótica; Cangaço e História do Brasil; Religião e Ex-voto e Escolas de Samba. Estes setores buscam oferecer uma visão abrangente do universo cultural brasileiro, compondo as variadas culturas rurais e urbanas do país. 0 Museu conta com um potente projeto educativo.

As motivações para que atividades educativas pudessem ser realizadas em museus e a implantação dessa ação teve início no Brasil em 1927, com a criação do Serviço de Assistência ao Ensino do Museu Nacional $^{5}$, pretendendo difundir as

\footnotetext{
${ }^{4}$ Área ocupada pelas exposições no período das visitações que deram ensejo ao presente artigo.

${ }^{5}$ Setor educativo institucionalizado no Brasil em 1927, o Serviço de Assistência ao Ensino do Museu Nacional, foi criado por Roquete Pinto. O Serviço tinha como missão auxiliar o desenvolvimento de práticas educativas que colaborassem com o aprendizado e com o currículo escolar. Instituto Brasileiro de Museus. Caderno da Política Nacional de Educação Museal. 2018, p. 14. Disponível em: https://www.museus.gov.br/wp-
}

ciências nas escolas, e, dessa maneira, desenvolver novas práticas que enriquecessem o aprendizado e o programa escolar, ainda que fosse reforçando a visão histórica construída pelas elites do país. Devido a sua importância e considerado um dos marcos da Museologia, o Seminário Regional Latino-Americano da UNESCO em 1958, no Museu de Arte Moderna no Rio de Janeiro, contribuiu para uma nova perspectiva pedagógica na esfera museal, e podemos observar:

O Seminário Regional da UNESCO, realizado na cidade do Rio de Janeiro em 1958, viabilizou a construção de um novo referencial teórico-prático no que se trata do fazer museológico e das próprias instituições ao discutir o papel educativo dos museus. $E$, a partir daí, o conceito de museu vai se ampliando, passando então a ser também compreendido como um espaço de educação para auxiliar nas atividades do ensino formal e como ferramenta didática, ou seja, uma espécie de extensão do espaço da escola. O documento elaborado a partir deste Seminário, a Declaração do Rio de Janeiro, apresentou uma preocupação dos profissionais de museus com as questões educativas, no âmbito da Museologia e dos museus. A questão educativa passa a ser mais enfatizada e assumida em um plano paralelo em relação às outras funções museológicas tradicionais. (SOTO, 2010, p. 31).

content/uploads/2018/06/Caderno-daPNEM.pdf. Acesso em: 5 jan. 2020. 
Entretanto, trabalhando com a história das contribuições na área da ciência, estudando e investigando processos educacionais em museus, Margaret Lopes, doutora em História Social, alerta sobre os cuidados na utilização de modelos de trabalho melhor adaptados para o público escolar nas instituições. Nesse caso, a prática pode trazer resultados mais eficazes para a comunicação dos objetos pertencentes ao museu, porém esta ação não deve ser incorporada como proposta permanente, pois resultaria em "museus escolarizados" (LOPES, 1991, p. 5).

A pesquisadora discorre ainda, utilizando a crítica sobre a "animação cultural em museus", feita por VarineBohan (1987) na ação educativa desenvolvida nesses espaços. O autor divide o tipo de abordagem em três categorias, quais sejam: terapêutica, promocional e conscientizante. Com características distintas a terapêutica e a promocional corresponderiam ao que o educador e filósofo Paulo Freire (1921-1997) chama de educação bancária ${ }^{6}$, já que a comunicação é

\footnotetext{
6 "Em lugar de comunicar-se, o educador faz "comunicados" e depósitos que os educandos, meras incidências, recebem pacientemente, memorizam e repetem" (FREIRE, 2005, p. 66).
}

feita em um único sentido. Dessa maneira, ainda de acordo com Lopes:

\begin{abstract}
A animação dos museus, em direção ao público escolar, não tem por objetivo, salvo muito raras exceções as necessidades deste público (sejamos francos e honestos) ou mesmo responder à demanda pedagógica expressa pelos professores. Se considerarmos a literatura sobre 0 assunto, se participarmos, como eu faço há muito tempo, de reuniões de educadores de museus, constataremos imediatamente que há para este tipo de animação somente duas motivações principais: justificar a existência da instituiçãomuseu e valorizar o patrimônio. (LOPES, 1991, p. 1).
\end{abstract}

Para completar a ideia de categorias em relação à abordagem no espaço museal, a conscientizante mais uma vez está relacionada a uma posição de Paulo Freire, sendo que nesse caso refere-se à educação libertadora.

Somamos à nossa reflexão, as experiências e inovações que vieram ocorrendo na educação,na busca de novas ideias relativas à mesma e troca de conhecimentos, e examinamos a noção de alfabetização cultural, que ganha significado quando contribui para a produção e reprodução de experiências culturais, ademais em relação aos grupos sociais. Dessa maneira, devemos dialogar com a proposta de Paulo Freire, na qual o educando pode reconhecer e 
CALABRE, Lia; COUTINHO, Rosely. Cultura popular e educação, uma experiência de visitação ao Museu Casa do Pontal. PragMATIZES -

Revista Latino-Americana de Estudos em Cultura, Niterói/RJ, Ano 11, n. 20, p. 90-108, março 2021.

compreender sua identidade cultural, a consciência de seus valores próprios, seja na memória pessoal ou coletiva, ou seja, pode-se enxergar uma ação cultural para a liberdade (como se intitula uma de suas obras). O autor nos mostra que: "[...] a criticidade e as finalidades que se acham nas relações entre os seres humanos e o mundo implicam em que estas relações se dão com um espaço que não é apenas físico, mas histórico e cultural". (FREIRE, 2003 apud COSTA; WAZENKESKI, 2015, p. 6).

O trabalho para promover a relação entre museus e educação ganha ainda destaque nos estudos e reflexões do professor Mário Chagas, ele nos alerta para a necessidade de se buscar, localizar, e conhecer como foram idealizados métodos para a educação em museus. O estudioso chama a atenção para o fato de que, além de considerar as diferenças culturais e até educacionais existentes no Brasil, vale observar que, de maneira mais ampla:

Para além da educação patrimonial ${ }^{7}$, interessa pensar a educação como

\footnotetext{
${ }^{7}$ A Educação Patrimonial constitui-se de todos os processos educativos formais e não formais que têm como foco o patrimônio cultural, apropriado socialmente como recurso para a compreensão sócio-histórica das referências culturais em todas as suas manifestações, a fim de colaborar para seu reconhecimento, sua
}

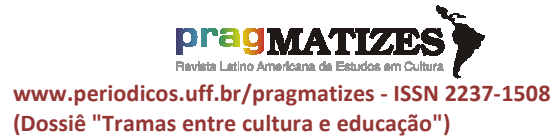

alguma coisa que não se faz sem se ter em conta um determinado patrimônio cultural e determinados aspectos da memória social; para além da educação patrimonial, interessa compreender a educação como prática social aberta à criação e ao novo, à eclosão de valores que podem nos habilitar para a alegria e a emoção de lidar com o diferente. (CHAGAS, 2004, p. 145).

É exatamente nesse sentido de prática social aberta à criação e ao novo, somado aos aspectos da memória social de um amplo segmento da sociedade que reconhecemos no trabalho desenvolvido pelo setor educativo da Casa do Pontal a habilidade de a partir da ludicidade trazer a alegria e a emoção de lidar com o diferente para alguns e descobrir o igual e a identidade para outros.

Para a compreensão do modo como se desenvolvem as atividades elaboradas para a visitação na referida instituição museal, trabalharemos com o Programa Social e Educacional do Museu Casa do Pontal. O documento tem como ponto central a integração

valorização e preservação. Considera-se, ainda, que os processos educativos devem primar pela construção coletiva e democrática do conhecimento, por meio da participação efetiva das comunidades detentoras e produtoras das referências culturais, onde convivem diversas noções de patrimônio cultural. Disponível em: http://portal.iphan.gov.br/pagina/detalhes/343. Acesso em: 21 mar.2020. 
CALABRE, Lia; COUTINHO, Rosely. Cultura popular e educação, uma experiência de visitação ao Museu Casa do Pontal. PragMATIZES -

Revista Latino-Americana de Estudos em Cultura, Niterói/RJ, Ano 11, n.

20, p. 90-108, março 2021.

da ação dos profissionais na facilitação de leituras das obras expostas visando a contribuir para a construção, por parte dos visitantes, de um conhecimento de maneira interativa e coletiva.O planejamento estratégico do referido programa, como ferramentas de gestão cultural,foi desenvolvido a partir do ano de 1996. Contou com a direção de Guy Van de Beuque (19512004), filósofo, matemático e filho do colecionador e fundador do museu, Jacques Van de Beuque, além da coordenação de Angela Mascelani, antropóloga, atual diretora do museu, escritora e curadora de arte.

Tal gestão reconhecia no acervo de arte popular uma propensão para a colaboração em processos de produção de conhecimento não tradicionais junto às escolas e para a mediação diferenciada junto aos grupos de visitantes.Nesse espaço de mediação entre o acervo e os visitantes atuariam os profissionais de arte educação. Ao examinar o movimento que se realizou na direção de expandir a relação dos alunos em visitação com esse espaço museal, podemos dizer que está apoiado na ideia de que:

A arte na educação como expressão pessoal e como cultura é um

www.periodicos.uff.br/pragmatizes - ISSN 2237-1508 (Dossiê "Tramas entre cultura e educação")

importante instrumento para a identificação cultural e o desenvolvimento. Através das artes é possível desenvolver a percepção e a imaginação, apreender a realidade do meio ambiente, desenvolver a capacidade crítica, permitindo analisar a realidade percebida e desenvolver a criatividade de maneira a mudar a realidade que foi analisada. (MAE BARBOSA, 2012).
\end{abstract}

A instituição prevê um papel estratégico para a área de arteeducação. Os responsáveis pelo programa consideraram que a formação dos profissionais envolvidos, deveria desenvolver e aperfeiçoar uma abordagem criativa, para que se pudessem ampliar as possibilidades de leitura e comunicação dos visitantes em relação ao acervo da instituição. Observa-se uma ação bem alinhada na definição do trabalho que deve ser realizado pelos educadores de museus segundo 0 Comitê Educativo do Sistema Estadual de Museus de São Paulo com o conceito:

Os educadores de museu são responsáveis por ampliar a relação entre o museu e seus públicos, sendo mediadores do objeto do museu e do público visitante, no momento do fato museal. Ao agir neste encontro (fato museal) 0 educador atua no processo de manter contemporâneo o caráter comunicacional do patrimônio, manifestando a latência significativa dos objetos. (SISEM-SP, 2016, p. 6). 
CALABRE, Lia; COUTINHO, Rosely. Cultura popular e educação, uma experiência de visitação ao Museu Casa do Pontal. PragMATIZES -

Revista Latino-Americana de Estudos em Cultura, Niterói/RJ, Ano 11, n. 20, p. 90-108, março 2021.

A aprovação da Política Nacional de Educação Museal (PNEM), definida no $7^{\circ}$ Fórum Nacional de Museus - Porto Alegre/2017, reúne os princípios e diretrizes que têm como objetivos nortear a realização das práticas educativas, fortalecer a dimensão educativa e subsidiar a atuação dos educadores em museus. Orienta as ações educacionais, no eixo II em relação aos profissionais, formação e pesquisa, com as seguintes diretrizes:

1. Promover o profissional de educação museal, incentivando o investimento na formação específica e continuada de profissionais que atuam no campo.

2. Reconhecer entre as atribuições do educador museal: a atuação na elaboração participativa do Programa Educativo Cultural; a realização de pesquisas e diagnósticos de sua competência; a implementação dos programas, projetos e ações educativas; a realização do registro, da sistematização e da avaliação dos mesmos; e promover a formação integral dos indivíduos.

3. Fortalecer o papel do profissional de educação museal, estabelecendo suas atribuições no Programa Educativo e Cultural e em conformidade com a Política Nacional de Educação Museal.

4. Valorizar o profissional da educação museal, incentivando a formalização da profissão, o estabelecimento de planos de carreira, a realização de concursos públicos e a criação de parâmetros nacionais para a equiparação da remuneração nas várias regiões do país.

5. Potencializar o conhecimento específico da educação museal de forma a consolidar esse campo, por meio da difusão e promoção dos www.periodicos.uff.br/pragmatizes - ISSN 2237-1508 (Dossiê "Tramas entre cultura e educação")

trabalhos realizados, do intercâmbio de experiência e do estímulo à viabilização de cursos de nível superior em educação museal.

6. Valorizar a troca de experiências por meio de parcerias nacionais e internacionais para a realização de estágios profissionais em educação museal.

7. Fortalecer a pesquisa em educação em museus e em contextos nos quais ocorrem processos museais, reconhecendo esses espaços como produtores de conhecimento em educação.

8. Promover o desenvolvimento e a difusão de pesquisas específicas do campo por meio da articulação entre os setores educativos e agências de fomento científico, universidades e demais instituições da área.

9. Promover, em colaboração com outros setores dos museus, diagnósticos, estudos de público e avaliação, visando à verificação do cumprimento de sua função social e educacional. ${ }^{8}$ (IBRAM, 2018).

A utilização da arte educação,nas visitas guiadas, como meio de apresentação do seu acervo, faz do Museu Casa do Pontal uma referência, seja em proporcionar ao visitante, nesse caso o aluno, o reconhecimento, apreciação e valorização da arte popular brasileira, seja em possibilitar a construção de laços de identidade.

\section{A experiência da visitação}

A seguir serão apresentadas experiências vivenciadas por quatro

8 Diretrizes para a realização das práticas educativas - EIXO II - PNEM. Disponível em: https://pnem.museus.gov.br/sobre-opnem/diretrizes/. Acesso em: 10 jan. 2020. 
turmas diferentes de alunos do Ensino Fundamental I, com crianças na faixaetária entre 7 e 11 anos, da rede pública de ensino do município do Rio de Janeiro, em visitação ao Museu Casa do Pontal, e acompanhadas no período intermitente de agosto de 2018 a setembro de 2019. A ideia é a de fortalecer a tese de que os processos não tradicionais de aprendizagem, associando elementos de cultura, arte e educação podem cumprir um papel fundamental na formação escolar democrática e plural desses jovens cidadãos.

Vamos proceder à descrição do processo de visitação. Ao estabelecer um agendamento para os grupos, o setor receptivo do museu organiza a visita teatralizada, com horários determinados e número exato de pessoas. Tal procedimento permite uma interação maior entre o grupo de visitantes com o museu. Dando início ao evento ${ }^{9}$ da visitação, o acolhimento acontece no espaço externo da instituição, pela equipe do local, quando os visitantes realizam um lanche e posteriormente são orientados a se posicionarem no pátio,

${ }^{9}$ O processo de visitação é composto por etapas e diferentes performances, o que nos permite falar em evento. formando um grande círculo de pessoas. Sendo assim, dispostos em roda, tem início a cantoria!

Ao som de violão, os arte educadores - Chico Lá e Pedro -, cumprimentam a todos: "Bom dia/ bom dia/ eu cheguei agora/ viemos de longe/ lá do mar lá fora..." Entre uma cantoria e outra, as letras das músicas e a viola apresentam conteúdos e elementos da cultura popular. Nesse momento há o convite para o jogo teatral, envolvendo os espectadores infantis que se voluntariam, tornandose personagens ao sabor da brincadeira.

O convite é para participar da encenação do Auto do Bumba-Meu$\mathrm{Boi}^{10}$, para que as crianças assumam papéis de criaturas com características folclóricas, de experimentação diante de acontecimentos misteriosos e sobrenaturais que 0 enredo do folguedo apresenta:

O bumba-meu-boi é um auto, onde o tema principal é a morte e a ressurreição de um boi. O enredo básico do bumba-meu-boi conta a história de um boi de estimação de um fazendeiro rico que é morto pelo

\footnotetext{
${ }^{10}$ O Bumba-Meu-Boi é um dos folguedos mais tradicionais do país e existe em quase todas as regiões. É encenado durante muitas épocas do ano, com ênfase nos meses de junho, julho e dezembro. É um auto, onde o tema principal é a morte e ressurreição de um boi (MASCELANI, 2009, p. 92.).
} 
empregado negro, Pai Francisco. Pai Francisco mata o boi para atender ao pedido de sua esposa, Catarina, que está grávida e sente desejo de comer a língua do animal. Descoberto como autor do crime, Pai Francisco confessa e é levado preso. Mas, por intermédio da magia praticada por um curandeiro indígena, o boi ressuscita, Pai Francisco é perdoado e tudo termina bem, dando motivo para os cantos, as danças e a alegria. ${ }^{11}$

Nesse contexto, é evidente o aporte que o teatro oferece para que haja o desenvolvimento de habilidades como a criatividade, memorização e o improviso, em um processo de aprendizagem com ludicidade. A peça ocorre de maneira espontânea e divertida na narrativa do "boi", e diferente do trabalho realizado nas escolas com a temática do folclore, por vezes reduzido a um conteúdo curricular, há nesse momento a compreensão e a vivência do que é cultura popular, e que esta vem da arte e do trabalho de todos.

O diálogo, como prática presente durante todo o evento, ganha destaque quando se pretende apreender a atenção das crianças, bem como obter a compreensão das mesmas, a respeito daqueles fazeres. Indagados sobre que tipo de obras elas encontrariam no interior do

\footnotetext{
${ }^{11}$ Site institucional do Museu Casa do Pontal (2012).
}

museu, e após emitir variadas opiniões, as crianças conhecem a aprazível definição: "coleção de bonequinhos". E, seguindo a abordagem, surge uma questão, sobre "Quem entre as crianças mantinha o hábito de colecionar e quais seriam os objetos colecionados?" Diante de grande interesse e participação, inúmeras respostas revelaram colecionadores de tampinhas, cartas, canetinhas, figurinhas, entre outros. Posto por meio do diálogo, um importante requisito de preparação para o início da visita, constata-se que muitos gostam e preservam suas coleções.Percebe-se que:

O hábito de colecionar presente na infância mostra que nessa fase há um grande interesse e valorização da cultura material. Contudo, é necessário que as mensagens contidas nas exposições sejam atrativas e de fácil compreensão para qualquer público não especialista no tema. Logo, os museus têm o desafio crucial de criar narrativas que valorizem a cultura material de forma a construir conhecimentos e valores de forma atrativa, que instigue $o$ visitante a desejar e buscar informações sobre o tema. (CARVALHO; LOPES, 2016).

Prosseguindo na descrição da dinâmica de visitação,quando um convite para ingressar então na área interna do museu é feito para a turma, a linguagem é musical,com ritmos e 
rimas. Nesse espaço onde se encontra a exposição permanente, as obras estão dispostas em galerias, organizadas em setores por temáticas. Com roteiros que apresentam o artista e sua obra, os alunos descobrem o escultor Antônio de Oliveira ${ }^{12}$ (1912 1996), que com sua obra conta histórias de seu "mundo encantado". O artesão ganha destaque, pois só trabalha com madeira, o que gera a rima, rapidamente assimilada pelo grupo: "Antônio de Oliveira/ Só trabalha com madeira/ $E$ quem trabalha com madeira? / É o Antônio de Oliveira". Tais obras despertam atenção especial, tendo em vista a reação provocada nas crianças ao contemplá-las.Nesse caso, se faz presente a relação de potencialidades presentes no uso da arte educação, proporcionando uma facilitação da compreensão dos processos técnicos empregados pelos artistas, seja na apropriação da cerâmica ou no entalhe da madeira. A ideia é estimular a

\footnotetext{
${ }^{12}$ Antônio de Oliveira (1912-1996), nasceu em Minas Gerais. O artista dedicou-se prioritariamente a esculpir em madeira. Entregou-se com paixão à recriação de cenas reais ou imaginárias, que compunham o que chamava de "meu mundo encantado". Site institucional do Museu Casa do Pontal. Disponível em: http://www.museucasadopontal.com.br/ant\%C 3\%B4nio-de-oliveira. Acesso em: 10 jan. 2020.
}

percepção das situações cotidianas retratadas através das obras, além da identificação no que diz respeito às manifestações culturais e consequentemente aos próprios costumes ali representados.

Um outro ponto alto no processo interativo da visitação é o da chegada ao Tocador de realejo, do artista Adalton Fernandes Lopes ${ }^{13}$ (1938-2005), que deu som e movimento ao "boneco". Os temas abordados pelos arte educadores nessa interação entre visitante e obra são "sorte" ou "azar",representada pelo fazer dessa figura muito popular.

O "Tocador de realejo" é uma mistura de músico de rua e tirador de sorte, muito comum até poucas décadas atrás. Anunciando sua presença através da música do realejo - uma espécie de instrumento musical portátil, cuja sonoridade lembra a do órgão -, oferecia-se para decifrar o futuro de quem interessava-se, no que era ajudado por um papagaio. A pessoa fazia uma pergunta e o papagaio escolhia a resposta numa caixa de cartõezinhos coloridos em que

\footnotetext{
${ }^{13}$ Adalton Fernandes Lopes (1938-2005) é dotado de rica imaginação. Suas obras evidenciam a observação perspicaz do cotidiano e das alegrias da vida mundana. Obcecado pelo desejo de "dar vida" a seus personagens, criou engenhocas imensas, onde centenas de figuras articuladas movimentam-se animadamente. Seus "bonecos" são inconfundíveis e apresentam uma visão especial da vida urbana. Site institucional do Museu Casa do Pontal. Disponível em: http://www.museucasadopontal.com.br/ptbr/node/13. Acesso em: 10 jan. 2020.
} 
estavam escritas as palavras portadoras da sorte. A melodia do realejo era produzida pelo movimento mecânico de um cilindro dentado, acionado à mão. Ao girar a manivela, o som animava as ruas e atraía as pessoas. (MASCELANI, 2009, p. 63).

A participação na experiência de interação com essa obra está relacionada à questão da superstição ${ }^{14}$ "sorte" ou "azar", que são conceitos de cultura popular. Ainda que não seja um conteúdo escolar propriamente dito, essa abordagem favorece o exercício reflexivo, pois está ligada ao que "está por vir", é alusiva ao futuro. Nesse caso, todos querem participar, "girar a manivela" e prever o futuro.

No interessante setor onde expressam a temática denominada Ciclo da Vida ${ }^{15}$ estão em exposição obras que mostram uma visão das fases da vida social, do nascimento, infância, meninice, juventude, maturidade e velhice. Durante a

\footnotetext{
${ }^{14}$ Atribuição do poder de atrair a sorte ou o azar a determinados objetos ou atos (Dicionário Aulete).

${ }^{15}$ Este setor oferece uma visão desta dinâmica social no Brasil, em determinadas regiões e épocas particulares. Olhando a vida humana como um ciclo, pensa-se no que é comum a todos, sobretudo da vida que transcorre em sociedade: nascimentos, infância, meninice, juventude, maturidade e velhice. Site institucional do Museu Casa do Pontal. Disponível em:

http://www.museucasadopontal.com.br/ptbr/taxonomy/term/469. Acesso em: 10 jan. 2020.
}

movimentação percebe-se intenso envolvimento e curiosidade por parte dos alunos, pois as obras estão dispostas em ordem cronológica, e a ideia de continuidade conta a história desde o nascimento até a hora da derradeira morte. O artista Antônio de Oliveira, mais uma vez ascende com seus bonecos na obra denominada Escada da Vida, provoca o interesse das crianças, incita a imaginação. E se o assunto é brincadeira tem para quem quiser, e pode "brincar de roda" e pode "pular carniça" - Brincadeiras de meninos e Brincadeiras de meninas.

$$
\text { No passeio pelo acervo, a }
$$
diversão é garantida assim como vai se dando uma aproximação aos elementos da cultura popular. Chega a hora do Circo. Com a pergunta feita "Hoje tem marmelada?" / Tem sim senhor! la atração surge na grande obra que retrata o tema, uma geringonça, ou seja, uma engenhoca onde as figuras são articuladas e movimentam-se, do artista Adalton, de onde é difícil desviar a atenção da garotada. A interação é quase que instantânea, pois todos querem comentar com os colegas suas experiências reais no passeio ao circo, sobre os tombos do palhaço e os 
riscos dos trapezistas. E há também quem diga "nunca fui ao circo!".

O conjunto de obras de Vitalino Pereira dos Santos, o Mestre Vitalino ${ }^{16}$ (1909-1963) compõe um setor de destaque na exposição permanente do Museu Casa do Pontal.O artista criou e interpretou ao longo de sua vida 118 diferentes temas como: o imaginário nordestino, a representação de ritos de passagem (nascimento, casamento e morte), assuntos relativos ao crime e à lei, a religião, a seca, a migração, o trabalho, as profissões, entre outros. A partir de uma narrativa sobre a vida e obra do artista, que inicia ainda quando era um menino pobre que acompanhava sua mãe para o trabalho na feira de Caruaru e, aos seis anos, já modelava boizinhos em barro para brincar. Diante disso, a identificação dos alunos com o Mestre é imediata.

A movimentação é constante durante toda visitação das turmas, não há monotonia, e o teatro popular de bonecos com música e bandinha

\footnotetext{
${ }^{16}$ Mestre Vitalino (1909-1963) criou uma narrativa visual expressiva sobre a vida no campo e nas vilas do nordeste pernambucano. Realizou esculturas antológicas, como $\mathrm{O}$ enterro na rede; Cavalo marinho; Casal no boi e muitas outras, de poética irretocável. Site institucional do Museu Casa do Pontal. Disponível em: http://www.museucasadopontal.com.br/ptbr/node/79. Acesso em: 10 jan. 2020.
}

propõe mais participação. Baseado na cantiga popular "O Cravo brigou com a Rosa" esse momento arranca muitas risadas. De improviso, o teatro de mamulengos estimula a oralidade e a criatividade dos meninos e meninas, além de proporcionar um processo de organização lógica de ideias para determinar o rumo da história, já que tudo é feito na base do improviso.

E quando a visita está prestes a terminar? Nessa cultura, "tudo acaba em samba!" Diante da obra Desfile de escolas de samba, do artista Adalton, o grupo interage, participa, se expressa. O escritor Rubem Alves (1933-2014) traduz bem esses momentos de ativamento dessa memória auditiva:

O mundo está cheio de música. Há os sons que não existem mais, que estão perdidos na memória. $A$ música do realejo, o canto do carro de bois, o apito das fábricas, das locomotivas, o din-din dos bondes, o canto dos galos, o repicar fúnebre dos sinos, a gaita do sorveteiro, a buzina das charretes... Parece que a poesia fica guardada nos sons que não mais se ouvem. [...] Há também os sons da cidade [...] $E$ há os sons da natureza [...] A primeira poesia que se ouve é uma canção de ninar. Depois, é a música do mundo... (ALVES, 2018).

\section{Contribuição das experiências - a}

\section{interface entre cultura e educação}

Mas afinal, o que levar em consideração, como fatores positivos, 
CALABRE, Lia; COUTINHO, Rosely. Cultura popular e educação, uma experiência de visitação ao Museu Casa do Pontal. PragMATIZES -

Revista Latino-Americana de Estudos em Cultura, Niterói/RJ, Ano 11, n.

20, p. 90-108, março 2021.

do encontro entre a cultura popular e grupos de alunos de escolas do ensino regular? O espaço oferecido para tal experiência?A possibilidade de sair da escola e passear? Vamos tecer algumas considerações a respeito desse relato.

O acompanhamento e observação de todo o processo de visitação das turmas regulares de ensino nos revela que este é um evento dinâmico com alto potencial participativo. Durante todo o evento ocorrem inúmeros questionamentos e colocações orais dos alunos que nos permitem perceber, claramente, o interesse e o grau de interação dos mesmos em relação às obras apreciadas no museu. Tal comunicação entre as crianças e os profissionais de arte educação da instituição, permite que essa experiência de educação não formal se transforme em momentos de intensa aprendizagem, prazer e deleite. A ludicidade das atividades, aliada à visualização de atividades que muitas vezes ainda integram a rotina ou trazem um dado de realidade às narrativas memorialistas do ambiente familiar tecem elos de identidade e pertencimento. É importante retomar

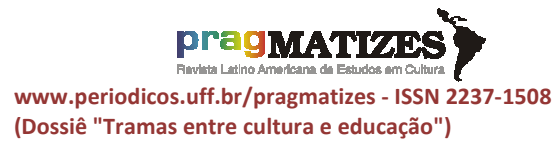

aqui $\mathrm{o}$ fato de que as experiências vivenciadas e aqui rapidamente apresentadas foram de visitas com turmas de alunos regulares e com a presença da professora regente e de algumas responsáveis de alunos. Devemos ainda acrescentar que muitas dessas crianças são de famílias com origem nordestina $e$, muitas vezes, rural. Através do Museu e dos artistas ali presentes os alunos têm uma pequena amostra da importância e da diversidade da cultura brasileira, com uma ênfase na valorização dos fazeres e saberes das culturas populares.

Tendo em vista que, ao contrário de supor que o ambiente museal pudesse determinar um comportamento formal por parte das crianças, o que se observou foi um protagonismo infantil, espontâneo, durante as explicações e brincadeiras.O ambiente, apesar de desconhecido, a partir das atividades da arte educação em uma perspectiva de facilitação da apropriação do conteúdo torna-se estimulador da participação. Vale lembrar, que o movimento de incentivo para que as atividades e experiências educacionais ultrapassem os muros da escola, 
CALABRE, Lia; COUTINHO, Rosely. Cultura popular e educação, uma experiência de visitação ao Museu Casa do Pontal. PragMATIZES -

Revista Latino-Americana de Estudos em Cultura, Niterói/RJ, Ano 11, n.

20, p. 90-108, março 2021.

ocupando novos lugares e ambientes, tem o potencial de gerar processos de enriquecimento cultural que transpõem práticas tradicionais escolarizadas.

As visitas ao Museu, em todas as turmas acompanhadas, puderam ser desdobradas em inúmeras atividades realizadas posteriormente em sala de aula. Processo de memorização de cantigas, atividades com desenhos e técnicas de moldagem de barro, reedição das brincadeiras, são algumas das atividades que puderam ser trabalhadas em sala de aula após a visitação. Em algumas das visitas os responsáveis que acompanhavam a visita não se contiveram e deram seus testemunhos sobre formas dos fazeres ali representados nos "bonequinhos de Vitalino", ou sobre as variações das brincadeiras nas suas localidades de origem, contribuindo, de alguma maneira, para a valorização e o reconhecimento das crianças naquelas memórias dos migrantes desterritorializados e subalternizados.

Certamente, a identificação autêntica dos meninos e meninas com a cultura popular brasileira, a própria cultura, exposta no Museu Casa do Pontal, serve como comprovação dos

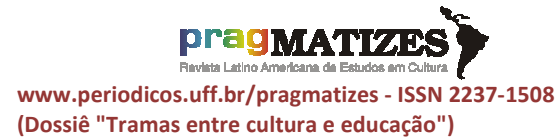

resultados positivos em relação aos conceitos de educação museal adotados pela instituição. $\mathrm{O}$ teatro, as músicas, brincadeiras e o diálogo nesse ambiente são recursos de um processo inovador, para além da educação formal, na direção da transformação da sociedade e suas relações.

\section{Referências bibliográficas}

ALVES, Rubem. A educação dos sentidos: conversas sobre a aprendizagem e a vida. São Paulo: Planeta do Brasil, 2018. E-book.

BRASIL. Lei 11.904 de 14 de janeiro de 2009. Institui o Estatuto de Museus, e dá outras providências. Diário Oficial da União, Brasília, 15 jan. 2009. Disponível em: http://www.planalto.gov.br/ccivil_03/_At o2007-2010/2009/Lei/L11904.htm.

Acesso em: 21 ago. 2020.

CARVALHO, Cristina; LOPES, Thamiris. $O$ público infantil nos museus. Educ. Real., Porto Alegre, v.41, n. 3, jul./set. 2016; EpubJune 07, $2016 . \quad$ Disponível em: http://www.scielo.br/scielo.php?script= sci_arttext\&pid=S2175-

62362016000300911\#B7. Acesso em: 5 jan. 2020.

CHAGAS, Mario. Diabruras do Saci: museu, memória, educação e patrimônio. Revista Musas, n. 1, p. 134-146, 2004. Disponível em: https://www.museus.gov.br/wpcontent/uploads/2011/04/Musas1.pdf. Acesso em: 4 jun. 2019.

CHAGAS, Mario. O seminário regional da Unesco sobre a função educativa 
CALABRE, Lia; COUTINHO, Rosely. Cultura popular e educação, uma experiência de visitação ao Museu Casa do Pontal. PragMATIZES -

Revista Latino-Americana de Estudos em Cultura, Niterói/RJ, Ano 11, n. 20, p. 90-108, março 2021

dos museus (1958): sessenta anos depois. In: CHAGAS, Mario; RODRIGUES, Marcus Vinicius Macri (org.). A função educacional dos museus: 60 anos do Seminário Regional da Unesco. Rio de Janeiro: Museu da República, 2019, p. 13.

COSTA, Heloisa Helena Fernandes Gonçalves da; WAZENKESKI, Verlaine Fátima. A importância das ações educativas nos museus. Revista de História e Geografia Ágora, v. 17, n. 2, p. 64-73, 2015. Disponível em: https://online.unisc.br/seer/index.php/a gora/article/view/6336/4837. Acesso em: 4 jun. 2019.

FREINET, Célestin. Um olhar sobre a práxis Freinetiana: aprendizagem em diferentes perspectivas: uma introdução. 2015. Disponível em: https://educimat.cefor.ifes.edu.br/imag es/stories/Publica\%C3\%A7\%C3\%B5e s/Livros/Livro-1-Aprendizado-emdiferentes-

perspectivas_2015.pdf\#page=116.

Acesso em: 10 jan. 2020.

FREIRE, Paulo. Pedagogia do oprimido. São Paulo: Editora Paz e Terra, 2005.

IBRAM. Instituto Brasileiro de Museus. Caderno da Política Nacional de Educação Museal. Brasília: IBRAM, 2018. Disponível em: https://www.museus.gov.br/wpcontent/uploads/2018/06/Caderno-daPNEM.pdf. Acesso em: 05 jan. 2020.

IBRAM. Instituto Brasileiro de Museus. Diretrizes para a realização das práticas educativas - EIXO II - PNEM. Disponível em: https://pnem.museus.gov.br/sobre-opnem/diretrizes/. Acesso em: 10 jan. 2020 .

IPHAN. Instituto do Patrimônio Histórico e Artístico Nacional. Educação Patrimonial. Disponível em: http://portal.iphan.gov.br/pagina/detalh es/343. Acesso em: 21 mar. 2020.

LOPES, Margaret Maria. A favor da desescolarização dos museus. Educação \& Sociedade, n. 40, dez. 1991. Disponível em: https://www.sisemsp.org.br/blog/wpcontent/uploads/2016/04/A-favor-dadesescolariza\%C3\%A7\%C3\%A3odos-museus.pdf. Acesso em: 21 set. 2019.

MAE BARBOSA, Ana. Arte, educação e cultura. 2012. E-book. Disponível em:

http://www.dominiopublico.gov.br/down load/texto/mre000079.pdf. Acesso em: 15 nov. 2018.

MASCELANI, Angela. [Entrevista cedida a] Ivan Vieira. A Casa, 10 jul. 2014. Disponível em: http://www.acasa.org.br/biblioteca/text o/514. Acesso em: 15 set. 2019.

MASCELANI, Angela. O mundo da arte popular brasileira: Museu Casa do Pontal. Rio de Janeiro: Mauad. 2009.

MUSEU CASA DO PONTAL. Site institucional Disponível em: http://www.museucasadopontal.com.br . Acesso em: 9 nov. 2019.

POEL, Francisco Van Der. Arte e artista popular. Textos Escolhidos de Cultura e Arte Populares, v. 9, n. 2, 2012.

ROLNIK, Suely. Subjetividade em obra: Lygia Clark artista contemporânea. 2002. Disponível em: https://revistas.pucsp.br/revph/article/vi ewFile/10571/7862. Acesso em: 05 jan. 2020. 
SISEM-SP. Conceitos-chave da educação em museus. 2016. Disponível em:

https://www.sisemsp.org.br/blog/wpcontent/uploads/2016/04/Bases-paraa-Pol\%c3\%adtica-Nacional-de-

Museus.pdf. Acesso em: 5 out. 2019.

SOTO, M. Quem educa no Templo das Musas? Reflexões e caminhos ao pensar a formação dos educadores em museus. 2010. Dissertação (Mestrado) - Universidade Lusófona de Humanidades e Tecnologias; Departamento de Arquitectura, Urbanismo, Geografia e Artes, Lisboa, 2010. 